\title{
A Review of Pesticide Exposure and Cancer Incidence in the Agricultural Health Study Cohort
}

\author{
Revisão sobre a exposição aos pesticidas e a incidência de câncer \\ em estudo de coorte da saúde dos agricultores
}

Scott Weichenthal ${ }^{1}$ Connie Moase ${ }^{1}$ Peter Chan ${ }^{1}$
${ }^{1}$ Health Canada. 269 Laurier Avenue West. K1A 0K9 Ottawa Ontario Canada.scott.weichenthal@ hc-sc.gc.ca

\begin{abstract}
We reviewed epidemiologic evidence related to occupational pesticide exposures and cancer incidence in the Agricultural Health Study (AHS) cohort. Studies were identified from the AHS publication list available on a Medline/ PubMed database search in March 2009. Findings related to lifetime-days and/or intensityweighted lifetime-days of pesticide use are the primary focus of this review, because these measures allow for the evaluation of potential exposure-response relationships. Most of the 32 pesticides examined were not strongly associated with cancer incidence in pesticide applicators. Increased rate ratios and positive exposure-response patterns were reported for 12 pesticides currently registered in Canada and/or the United States. Exposure misclassification is also a concern in the AHS and may limit the analysis of exposureresponse patterns. Epidemiologic evidence outside the AHS remains limited with respect to most of the observed associations, but animal toxicity data support the biological plausibility of relationships observed six pesticides. Continued follow-up is needed to clarify associations reported to date. In particular, further evaluation of registered pesticides is warranted.
\end{abstract}

Key words Agricultural health study, Cancer, Pesticides, Review
Resumo Nós revisamos evidências epidemiológicas relacionadas à exposição ocupacional a pesticidas e à incidência de câncer no Estudo da Saúde Agrícola (AHS). Descobertas relacionadas com a vida-dia e / ou intensidade do tempo de vidadia do uso de agrotóxicos são o foco principal desta revisão, porque estas medidas permitem a avaliação do potencial das relações de exposição-resposta. A maioria dos 32 pesticidas examinados não foram fortemente associados à incidência de câncer em aplicadores de pesticidas. Um aumento da taxa e padrões de resposta-exposição positivos foram reportados em 12 pesticidas registrados atualmente nos Estados Unidos e Canadá. A classificação de exposição incorreta também é uma preocupação para o AHS e pode limitar a análise dos padrões de resposta-exposição. É necessário um acompanhamento contínuo para clarificar as associações reportadas até hoje. Em particular, é necessária uma avaliação mais profunda dos pesticidas registrados.

Palavras-chave Estudo de saúde agrícola, Câncer, Pesticidas, Revisão 
Agricultural workers are exposed to a variety of chemical, physical, and biological hazards in the process of cultivating and harvesting crops and/ or raising livestock (Litchfield 1999; Popendorf and Donham 1991; Shaver and Tong 1991; White and Cessna 1989). In addition to pesticides, occupational exposure to solvents, metals, engine exhaust, welding fumes, and grain dusts are prevalent in agriculture (Coble et al. 2002; Shaver and Tong 1991). However, the potential health effects of agricultural pesticide exposures are of particular interest, as these chemicals are designed to have adverse biological effects on target organisms. To address this concern, the Agricultural Health Study (AHS) was initiated in 1993 to explore the potential health effects of pesticide exposures in commercial pesticide applicators, farmers, and their families in Iowa and North Carolina, USA. The AHS is a collaborative research project including the U.S. National Cancer Institute, the U.S. National Institute of Environmental Health Sciences, and the U.S. Environmental Protection Agency (EPA).

Details of the AHS design have been described previously (Alavanja et al. 1996). Briefly, participants were recruited between 1993 and 1997 from pesticide applicator licensing facilities in Iowa and North Carolina, and an enrollment questionnaire was used to collect data on the duration and frequency of pesticide use. In the AHS, self-reported pesticide use serves as a surrogate measure of pesticide exposure, and a cumulative pesticide exposure index (termed intensity-weighted exposuredays) is used to weigh lifetime-days (LDs) of pesticide use based on mixing conditions, application methods, and use of personal protective equipment (Dosemeci et al. 2002). Applicators who completed the enrollment questionnaire were asked to complete a take-home questionnaire that collected detailed information on factors including occupational exposures, pesticide use, lifestyle, medical history, and diet. Two additional take-home questionnaires were provided for private applicators: a spouse questionnaire and a female/family health questionnaire. Commercial applicators were asked to complete a female health questionnaire if they were female, but spouses and children of commercial applicators were not included in the AHS. A total of 52,395 private pesticide applicators (farmers or nursery workers), 32,347 spouses of private applicators, and 4,916 commercial pesticide applicators were enrolled in the AHS. Applicators are primarily male (> 95\%); spouses are predominantly female (99.3\%) (Alavanja et al. 2005). Private applicators, commercial applicators, and spouses are all predominantly Caucasian (94.6-98.6\%) (Alavanja et al. 2005). At enrollment, $65 \%$ of private applicators reported pesticide exposure for $>11$ years relative to $32 \%$ and $18 \%$ for commercial applicators and spouses of private applicators, respectively (Alavanja et al. 2005). Twelve percent of private applicators, $2.5 \%$ of commercial applicators, and $3.6 \%$ of spouses reported $>30$ years of pesticide use at enrollment (Alavanja et al. 2005). Information provided at enrollment (phase 1) was updated in phase 2 (1999-2003) and phase 3 (2003-2010) of the AHS.

Approximately $80 \%$ of eligible applicators completed the enrollment questionnaire (Tarone et al. 1997). Forty percent of eligible applicators completed both the enrollment questionnaire and the take-home questionnaire (Tarone et al. 1997). Seventy-four percent of eligible spouses were enrolled in the AHS (Engel et al. 2005). Applicators who completed the take-home questionnaire tended to be older than nonrespondents but were otherwise similar to respondents with respect to pesticide use practices, medical history, and other characteristics such as education, smoking, alcohol consumption, and diet (Tarone et al. 1997). The reliability of self-reported pesticide use did not vary substantially by age, education, or farm size, and respondents generally provided plausible information regarding the duration and year of first pesticide use (Blair et al. 2002; Hoppin et al. 2002b).

In this review we focused on epidemiologic studies of pesticide exposure and cancer incidence in the AHS cohort. Studies of physical injury (Sprince et al. 2002, 2003a, 2003b, 2003c, 2007), mortality (Blair et al. 2005a, 2005b; Lee et al. 2007a), respiratory disorders (Hoppin et al. 2002a, 2006a, 2006b, 2007a, 2007b, 2008; Valcin et al. 2007), neurologic symptoms (Kamel et al. 2005, 2007a), retinal degeneration (Kamel et al. 2000; Kirrane et al. 2005), diabetes (Montgomery et al. 2008; Saldana et al. 2007), menstrual cycle characteristics (Farr et al. 2004, 2006), hearing loss (Crawford et al. 2008), Parkinson's disease (Kamel et al. 2007b), changes in serum androgen levels (Martin et al. 2002), arthritis (De Roos et al. 2005b), depression (Beseler et al. 2006, 2008), and immune responses (Cooper et al. 2004) have also been conducted as part of the AHS but are not discussed in this review. 


\section{Methods}

We identified studies from the publication list on the AHS Web site (Agricultural Health Study 2009) and by searching the Medline/PubMed database (http://www.ncbi.nlm.nih.gov/sites/ entrez?db=pubmed) using the key words "Agricultural Health Study" and "pesticides" in combination with various cancer types including "leukemia," "prostate cancer," “colon cancer," and others. We also examined citation lists. Studies were included in this review if they were published before March 2009 and examined the relationship between pesticides and cancer in the AHS cohort. Findings related to LDs and/or intensity-weighted lifetime-days (IWLDs) of pesticide use are the primary focus of this review, because these measures allow for the evaluation of potential exposure-response relationships.

We identified 28 studies that examined the relationship between pesticide exposures and cancer incidence in the AHS cohort. A list of the pesticides and cancer types examined in these studies is provided in Supplemental Material (doi:10.1289/ehp.0901731). Prevalent cancer cases were excluded in all studies reviewed, and incident cases were identified by matching cohort members to state cancer registry files. Cohort members were matched to state death registries and the National Death Index to ascertain vital status, and current address records of the Internal Revenue Service, motor vehicle records, and pesticide license registries were used to identify cohort members who were alive at the end of follow-up but no longer resided in Iowa or North Carolina. Follow-up was censored at the time of cancer diagnosis, participant death, or movement out of state. In general, only a small fraction $(<$ $5 \%$ ) of study participants was lost to follow-up. Average follow-up times ranged from approximately 4 to 9 years, and when presented, standardized incidence ratios (SIRs) reflect cancer incidence in the AHS cohort relative to the populations of Iowa and North Carolina using age, sex, and race-specific incidence data. The primary pesticide exposure measures were LDs (the product of days of use per year and years of use) and IWLDs (a weighted measure of lifetime exposuredays that accounts for mixing conditions, application methods, and the use of personal protective equipment) (Dosemeci et al. 2002). Where appropriate, a number of potential confounding factors were included in Poisson/logistic regression models, including age, smoking history, al- cohol consumption, education, race, sex, applicator type, state of residence, LDs of any pesticide exposure, pesticides highly correlated with the pesticide of interest, family history of cancer, year of enrollment, body mass index, sun exposure, susceptibility to sunburn, aspirin intake, physical activity, nonfarm occupational exposures, diet, menopausal status, maternal age at first birth, age at menarche, and age at menopause. Findings were reported as rate ratios (RRs) or odds ratios (ORs) and their associated 95\% confidence intervals (CIs). Linear trend tests (alpha $=0.05)$ were used to evaluate exposure-response relationships by treating median values for each pesticide exposure category as a quantitative score or by using continuous values for LDs or IWLDs of exposure. Criteria for including a given cancer type in chemical-specific analyses (i.e., studies of one pesticide and multiple cancer types) differed between studies and ranged from a minimum total of 5 to 30 exposed cases. Alternatively, some authors specified that a given cancer type was included in chemical-specific analyses only if e" 4 cases were available in each category of exposure. In general, pesticides with $<5$ exposed applicators were excluded from cancerspecific analyses (i.e., studies of one cancer type and multiple pesticides). Values for the median number of exposed cases included in the studies we reviewed are listed in Supplemental Material (doi:10.1289/ehp.0901731).

\section{Results}

Study findings are summarized below for individual cancer types examined in the AHS cohort to date. Pesticides associated with cancer are listed in Table 1. A number of studies examined pesticide exposures according to both LDs and IWLDs of exposure. RRs (or ORs) for both exposure measures are included in Table 1 if at least one of these measures was associated with a significantly increased risk of cancer $(\mathrm{p}<0.05)$. ORs were reported by Alavanja et al. (2003, 2004), Andreotti et al. (2009), and Lee et al. (2007b), and all other studies in Table 1 reported RRs. All RRs and ORs in Table 1 refer to nonexposed applicators except those reported for alachlor and all lymphohematopoietic cancers (Lee et al. 2004b), dicamba and colon (Samanic et al. 2006), and lung cancer (Alavanja et al. 2004), which refer to applicators in the lowest category of exposure. 


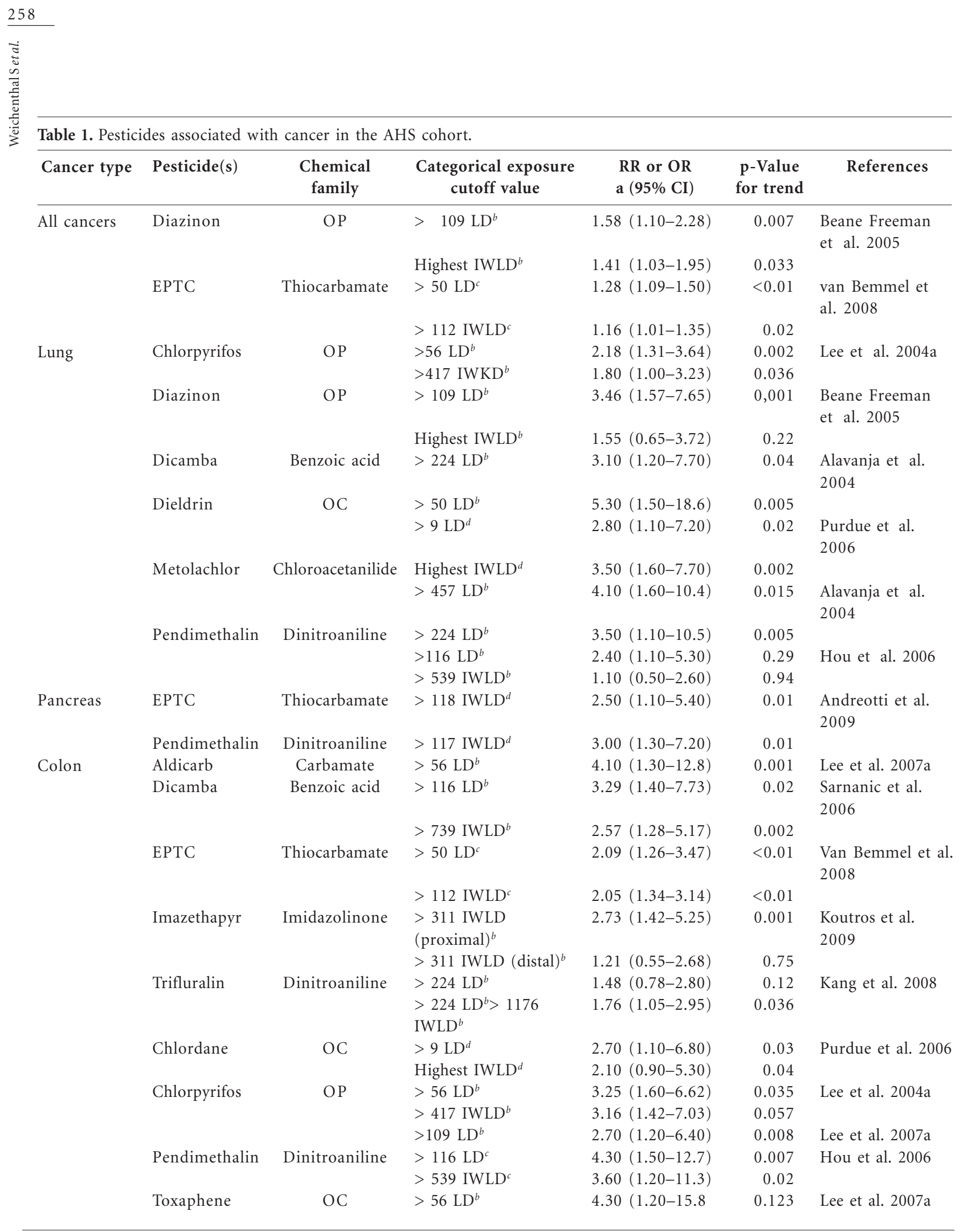

it continues

\section{Study Summaries}

All cancers. Overall cancer incidence was increased among applicators in the highest exposure categories for diazinon (Beane Freeman et al. 2005) and S-ethyl-N,N-dipropylthiocarbamate (EPTC) (van Bemmel et al. 2008) relative to nonexposed applicators, and significant exposure-response trends were observed for both pesticides with both exposure measures. None of the other pesticides 


\begin{tabular}{|c|c|c|c|c|c|c|}
\hline Cancer type & Pesticide(s) & $\begin{array}{l}\text { Chemical } \\
\text { family }\end{array}$ & $\begin{array}{c}\text { Categorical exposure } \\
\text { cutoff value }\end{array}$ & $\begin{array}{c}\text { RR or OR } \\
\text { a }(95 \% \mathrm{CI})\end{array}$ & $\begin{array}{l}\mathrm{p} \text {-Value } \\
\text { for trend }\end{array}$ & References \\
\hline \multirow[t]{9}{*}{ Leukemia } & $\begin{array}{l}\text { Chlordane/ } \\
\text { Heptachlor }\end{array}$ & $\mathrm{OC}$ & $>9 \mathrm{LD}^{d}$ & $2.60(1.20-6.00)$ & 0.02 & Purdue et al. 2006 \\
\hline & & & Highest IWLD ${ }^{d}$ & $2.10(0.80-5.50)$ & 0.10 & \\
\hline & Clorpyrifos & $\mathrm{OP}$ & $>56 \mathrm{LD}^{b}$ & $2.15(0.96-4.81)$ & 0.36 & Lee et al. $2004 \mathrm{a}$ \\
\hline & & & $>417 \mathrm{IWLD}^{b}$ & $3.01(1.35-6.69)$ & 0.15 & \\
\hline & Diazinon & $\mathrm{OP}$ & $>39 \mathrm{LD}^{c}$ & $3.36(1.08-10.5)$ & 0.026 & $\begin{array}{l}\text { Beane Freeman et } \\
\text { al. } 2005\end{array}$ \\
\hline & & & Highest IWLD ${ }^{c}$ & $2.88(0.92-9.03)$ & 0.053 & \\
\hline & EPTC & Thiocarbamate & $>50 \mathrm{LD}^{c}$ & $2.36(1.16-4.84)$ & 0.02 & $\begin{array}{l}\text { Van Bemmel et al } \\
2008\end{array}$ \\
\hline & & & $>112 \mathrm{IWLD}^{c}$ & $1.87(0.97-3.59)$ & 0.05 & \\
\hline & Fonofos & $\mathrm{OP}$ & $>609 \mathrm{IWLD}^{c}$ & $2.67(1.06-6.70)$ & 0.04 & $\begin{array}{l}\text { Mahajan et al. } \\
\text { 2006a }\end{array}$ \\
\hline \multirow[t]{8}{*}{ All LH } & Alachlor & Chloroacetanilide & $>116 \mathrm{LD}^{c}$ & $2.04(0.89-4.65)$ & 0.02 & Lee et al. $2004 \mathrm{~b}$ \\
\hline & & & $>710 \mathrm{IWLD}^{c}$ & $2.42(1.00-5.89)$ & 0.03 & \\
\hline & Chlorpyrifos & $\mathrm{OP}$ & $>56 \mathrm{LD}^{b}$ & $1.43(0.86-2.36)$ & 0.26 & Lee et al. $2004 \mathrm{a}$ \\
\hline & & & $>417 \mathrm{IWLD}^{b}$ & $1.99(1.22-3.26)$ & 0.09 & \\
\hline & Diazinon & $\mathrm{OP}$ & $>39 \mathrm{LD}^{c}$ & $1.84(0.89-3.82)$ & 0.094 & $\begin{array}{l}\text { Beane Freeman et } \\
\text { al. } 2005\end{array}$ \\
\hline & & & Highest IWLD $^{c}$ & $2.01(1.02-3.94)$ & 0.049 & \\
\hline & Permethrin & Pyrethroid & $>50 \mathrm{LD}^{c}$ & $1.64(1.07-2.52)$ & 0.35 & $\begin{array}{l}\text { Rusiecki et al. } \\
2009\end{array}$ \\
\hline & & & $>220 \mathrm{IWLD}^{c}$ & $1.31(0.84-2.04)$ & 0.60 & \\
\hline \multirow[t]{2}{*}{ NHL } & Lindane & $\mathrm{OC}$ & $>22 \mathrm{LD}^{d}$ & $2.10(0.80-5.50)$ & 0.12 & Purdue et al. 2006 \\
\hline & & & Highest IWLD ${ }^{d}$ & $2.60(1.10-6.40)$ & 0.04 & \\
\hline \multirow[t]{2}{*}{$\begin{array}{l}\text { Multiple } \\
\text { Myeloma }\end{array}$} & Permethrin & Pyrethroid & $>50 \mathrm{LD}^{c}$ & $5.72(2.76-11.8)$ & $<0.01$ & $\begin{array}{l}\text { Rusiecki et al. } \\
2009\end{array}$ \\
\hline & & & $>220 \mathrm{IWLD}^{c}$ & $5.01(2.41-10.4)$ & $<0.01$ & \\
\hline Bladder & Imazethapyr & Imidazolinone & $>311 \mathrm{IWLD}^{b}$ & $2.37(1.20-4.68)$ & 0.01 & $\begin{array}{l}\text { Koutros et al. } \\
2009\end{array}$ \\
\hline \multirow[t]{3}{*}{ Prostate } & Fonofos & $\mathrm{OP}$ & $>56 \mathrm{LD}^{c}$ & $1.77(1.03-3.05)$ & 0.02 & $\begin{array}{l}\text { Mahajan et al. } \\
2006 \text { (for } \\
\text { applicators with a } \\
\text { family history of } \\
\text { prostate cancer) }\end{array}$ \\
\hline & & & $>315 \mathrm{IWLD}^{c}$ & $1.83(1.12-3.00)$ & 0.01 & \\
\hline & Methylbromide & $\begin{array}{l}\text { Halogenated } \\
\text { alkane }\end{array}$ & Highest IWLD ${ }^{e}$ & $3.47(1.37-8.76)$ & 0.004 & $\begin{array}{l}\text { Alavanja et al. } \\
2003\end{array}$ \\
\hline \multirow[t]{2}{*}{ Brain } & Chlorpyrifos & $\mathrm{OP}$ & $>56 \mathrm{LD}^{b}$ & $2.58(0.73-9.17)$ & 0.076 & Lee et al. $2004 \mathrm{a}$ \\
\hline & & & $>417 \mathrm{IWLD}^{b}$ & $4.03(1.18-13.8)$ & 0.036 & \\
\hline \multirow[t]{4}{*}{ Melanoma } & Carbaryl & Carbamate & $>175 \mathrm{LD}^{b}$ & $4.11(1.33-12.7)$ & 0.07 & $\begin{array}{l}\text { Mahajan et al. } \\
2007\end{array}$ \\
\hline & & & $\begin{array}{l}\text { Highest intensity } \\
\text { score }^{b}\end{array}$ & $1.54(0.61-3.86)$ & 0.92 & \\
\hline & Toxaphene & OC & $>25 \mathrm{LD}^{d}$ & $2.90(1.10-8.10)$ & 0.03 & Purdue et al. 2006 \\
\hline & & & Highest IWLD $^{d}$ & $1.80(0.70-5.10)$ & 0.24 & \\
\hline
\end{tabular}

Abbreviations: LH, lymphohematopoietic cancers; OC, organochlorine; OP, organophosphate. ORs were reported by Alavanja et al. (2003, 2004), Andreotti et al. (2009), and Lee et al. (2007b); all others are RRs. aAll RRs and ORs were estimated relative to nonexposed applicators except those reported for alachlor and all LH (Lee et al. 2004b) and dicamba and colon (Samanic et al. 2006) and lung cancer (Alavanja et al. 2004), which are in reference to applicators in the lowest category of exposure. bHighest quintile. cHighest quartile. dHighest tertile. eHighest sixth.

examined were associated with a significant increase in overall cancer incidence (alachlor, atrazine, captan, carbaryl, carbofuran, chlorothalonil, cyanazine, dicamba, dichlorvos, fonofos, glyphosate, heptachlor, imazethapyr, malathion, metolachlor, pendimethalin, permethrin, phorate, and 
tri-fluralin) (Bonner et al. 2005, 2007; De Roos et al. 2005a; Greenburg et al. 2008; Hou et al. 2006; Kang et al. 2008; Koutros et al. 2008, 2009; Lee et al. 2004b; Lynch et al. 2006; Mahajan et al. 2006a, 2006b, 2007; Mozzachio et al. 2008; Rusiecki et al. 2004, 2006, 2009; Samanic et al. 2006).

Lung cancer. Applicators with the highest LDs of exposure to chlorpyrifos (Lee et al. 2004a), diazinon (Beane Freeman et al. 2005), dieldrin (Alavanja et al. 2004; Purdue et al. 2006), metolachlor (Alavanja et al. 2004), and pendimethalin (Alavanja et al. 2004; Hou et al. 2006) had increased lung cancer incidence relative to nonexposed applicators. Lung cancer risk was also significantly increased among applicators in the highest category of intensity-weighted dieldrin exposure days (Purdue et al. 2006), but diazinon and pendimethalin were not associated with lung cancer when exposures were analyzed according to this measure. Applicators with the highest LDs of dicamba exposure had increased lung cancer incidence relative to low-exposed applicators but not relative to nonexposed applicators $(\mathrm{OR}=1.6$; 95\% CI, 0.73.4) (Alavanja et al. 2004). Significant exposureresponse trends were observed for chlorpyrifos (Lee et al. 2004a), diazinon (Beane Freeman et al. 2005), dicamba (Alavanja et al. 2004), dieldrin (Alavanja et al. 2004; Purdue et al. 2006), metolachlor (Alavanja et al. 2004), and pendimethalin (Alavanja et al. 2004). However, the most recent study of pendimethalin exposure did not observe a significant exposure-response trend for lung cancer (Hou et al. 2006). Fourteen other pesticides were examined but were not associated with increased lung cancer incidence in pesticide applicators (atrazine, captan, carbaryl, chlorothalonil, cyanazine, dichlorvos, EPTC, fonofos, glyphosate, imazethapyr, malathion, permethrin, phorate, and trifluralin) (Alavanja et al. 2004; Bonner et al. 2007; De Roos et al. 2005a; Kang et al. 2008; Koutros et al. 2008, 2009; Greenburg et al. 2008; Mahajan et al. 2006a, 2006b, 2007; Mozzachio et al. 2008; Lynch et al. 2006; Rusiecki et al. 2004, 2009; Samanic et al. 2006; van Bemmel et al. 2008).

Pancreatic cancer. Applicators in the highest categories of intensity-weighted EPTC and pendimethalin exposure-days had an increased risk of pancreatic cancer relative to nonexposed applicators, and we observed significant exposureresponse trends for both pesticides (Andreotti et al. 2009). Eleven other pesticides were examined but were not associated with pancreatic cancer [alachlor, atrazine, chlorpyrifos, cyanazine, 2,4dichlorophenoxy acetic acid (2,4-D), dicamba, glyphosate, imazethapyr, metolachlor, terbufos, and trifluralin] (Andreotti et al. 2009; De Roos et al. 2005a; Rusiecki et al. 2004).

Colon and rectal cancer. Applicators with the highest LDs of exposure to aldicarb (Lee et al. 2007b), dicamba (Samanic et al. 2006), EPTC (van Bemmel et al. 2008), imazethapyr (Koutros et al. 2009), and trifluralin (Kang et al. 2008) had increased colon cancer incidence relative to nonexposed applicators. For imazethapyr, excess colon cancer incidence was limited to the proximal colon (Koutros et al. 2009); other studies did not examine colon cancer according to location. Significant exposure-response relationships were observed for aldicarb, dicamba, EPTC, imazethapyr, and trifluralin, but few cases were available in the first $(n=7)$ and second tertiles ( =4) of intensity-weighted EPTC exposure days. Applicators with the highest lifetime exposuredays for chlordane (Purdue et al. 2006), chlorpyrifos (Lee et al. 2004a; 2007b), pendimethalin (Hou et al. 2006), and toxaphene (Lee et al. 2007b) had increased rectal cancer risk relative to nonexposed applicators. Rectal cancer risk was also significantly increased when chlorpyrifos and pendimethalin exposures were analyzed according to IWLDs (Hou et al. 2006; Lee et al. 2004a), and we observed significant exposure-response trends for chlordane (Purdue et al. 2006), chlorpyrifos (Lee et al. 2004a; 2007b), and pendimethalin (Hou et al. 2006). Seventeen other pesticides were examined but were not associated with colon or rectal cancer incidence $(2,4-\mathrm{D}$, alachlor, aldrin, atrazine, captan, carbaryl, carbofuran, chlorothalonil, cyanazine, diazinon, dichlorvos, fonofos, glyphosate, malathion, metolachlor, permethrin, and phorate) (Beane Freeman et al. 2005; Bonner et al. 2005, 2007; De Roos et al. 2005a; Greenburg et al. 2008; Koutros et al. 2008; Lee et al. 2004b, 2007b; Lynch et al. 2006; Mahajan et al. 2006a, 2007; Mozzachio et al. 2008; Purdue et al. 2006; Rusiecki et al. 2004, 2006, 2009).

All lymphohematopoietic cancers. Applicators in the highest category of intensity-weighted alachlor exposure-days had an increased incidence of all lymphohemato-poietic cancers relative to low-exposed applicators (Lee et al. 2004b). Applicators in the highest categories of intensity-weighted exposure-days for chlorpyrifos (Lee et al. 2004a) and diazinon (Beane Freeman et al. 2005) had an increased incidence of all lymphohematopoietic cancers relative to nonexposed applicators, but RRs were not significantly increased when exposures were analyzed according to LDs of use. Applicators in the highest category of permethrin exposure-days had an increased incidence of all 
lymphohematopoietic cancers but the RR for the highest category of intensity-weighted permethrin exposure-days was not significantly increased (Rusiecki et al. 2009). Significant exposure-response trends were observed for alachlor (Lee et al. 2004b) and diazinon (Beane Freeman et al. 2005). Fifteen other pesticides were examined but were not associated with lymphohemato-poietic cancers (captan, carbaryl, carbofuran, cyanazine, dicamba, dichlorvos, EPTC, fonofos, glyphosate, imazethapyr, malathion, metolachlor, pendimethalin, phorate, and trifluralin) (Bonner et al. 2005, 2007; De Roos et al. 2005a; Greenburg et al. 2008; Hou et al. 2006; Kang et al. 2008; Koutros et al. 2008, 2009; Lee et al. 2004b; Lynch et al. 2006; Mahajan et al. 2006a, 2006b, 2007; Rusiecki et al. 2006; Samanic et al. 2006).

Leukemia. Applicators with the highest LDs of exposure for heptachlor/chlordane (Purdue et al. 2006), diazinon (Beane Freeman et al. 2005), and EPTC (van Bemmel et al. 2008) had increased leukemia incidence relative to nonexposed applicators. When exposures were analyzed according to intensity-weighted exposures-days, applicators in the highest categories of exposure for fonofos (Mahajan et al. 2006a) and chlorpyrifos (Lee et al. 2004a) also had increased leukemia incidence relative to nonexposed applicators. Significant dose-response relationships were observed for heptachlor/chlordane, diazinon, EPTC, and fonofos. Seven other pesticides were examined but were not associated with leukemia in pesticide applicators (alachlor, atrazine, carbaryl, glyphosate, imazethapyr, malathion, and trifluralin) (Bonner et al. 2007; De Roos et al. 2005a; Kang et al. 2008; Koutros et al. 2009; Mahajan et al. 2007; Rusiecki et al. 2004, 2009).

Non-Hodgkin lymphoma. Applicators in the highest category of intensity-weighted exposuredays for lindane had increased non-Hodgkin lymphoma (NHL) incidence relative to nonexposed applicators, and a significant exposure-response trend was observed (Purdue et al. 2006). However, we did not observe a significant trend for lindane when we analyzed exposures according to lifetime exposure-days. Sixteen other pesticides were examined but were not associated with NHL in pesticide applicators (alachlor, atrazine, carbaryl, carbofuran, chlorpyrifos, cyanazine, diazinon, dicamba, EPTC, glyphosate, imazethapyr, malathion, metolachlor, pendimethalin, permethrin, and trifluralin) (Beane Freeman et al. 2005; Bonner et al. 2005, 2007; De Roos et al. 2005a; Hou et al. 2006; Kang et al. 2008; Koutros et al. 2009; Lee et al. 2004a, 2004b; Lynch et al. 2006;
Mahajan et al. 2007; Rusiecki et al. 2004, 2006, 2009; Samanic et al. 2006; van Bemmel et al. 2008).

Multiple myeloma. Applicators in the highest categories of permethrin exposure had an increased incidence of multiple myeloma relative to nonexposed applicators, and we observed significant exposure-response patterns (Rusiecki et al. 2009). However, $\leq 3$ cases were available in the first and second tertiles of exposure; further evaluation of a potential exposure-response pattern is required once more cases have accrued. Four other pesticides were examined but were not associated with multiple myeloma (alachlor, atrazine, chlorpyrifos, and glyphosate) (De Roos et al. 2005a; Lee et al. 2004a, 2004b; Rusiecki et al. 2004).

Breast cancer. Engel et al. (2005) examined breast cancer incidence among farmers' wives. Breast cancer incidence was decreased among women who reported ever applying pesticides relative to the general population ( $\mathrm{SIR}=0.87$; 95\% CI, 0.89-1.24), and strong associations were not detected for specific pesticides. Ever use of pesticides in this study included use on crops and livestock as well as use in the home or garden. Although few women personally applied many of the pesticides examined, breast cancer incidence was increased among women whose husbands reported ever use of aldrin $(\mathrm{RR}=1.9 ; 95 \% \mathrm{CI}$, $1.3-2.7)$, carbaryl $(\mathrm{RR}=1.4 ; 95 \% \mathrm{CI}, 1.0-2.0)$, chlordane $(\mathrm{RR}=1.7 ; 95 \% \mathrm{CI}, 1.2-5.5)$, dieldrin $(\mathrm{RR}=2.0 ; 95 \% \mathrm{CI}, 1.1-3.3)$, heptachlor $(\mathrm{RR}=$ 1.6 ; 95\% CI, 1.1-2.4), lindane $(\mathrm{RR}=1.7 ; 95 \% \mathrm{CI}$, $1.1-2.5)$, malathion $(\mathrm{RR}=1.4 ; 95 \% \mathrm{CI}, 1.0-2.0)$, 2,4,5- trichlorophenoxypropionic acid (2,4,5-TP) $(\mathrm{RR}=2.0 ; 95 \% \mathrm{CI}, 1.2-3.2)$ or captan $(\mathrm{RR}=2.7$; 95\% CI, 1.7-4.3). RRs varied by menopausal status, with increased breast cancer incidence observed among premenopausal women ever exposed to chlorpyrifos $(\mathrm{RR}=2.2 ; 95 \% \mathrm{CI}, 1.0$ 4.9 ), dichlorvos ( $\mathrm{RR}=2.3$; 95\% CI, 1.0-5.3), or terbufos $(\mathrm{RR}=2.6 ; 95 \% \mathrm{CI}, 1.1-5.9)$ but not among postmenopausal women. Potential exposure-response patterns were not examined in this study because pesticide exposure information was limited to ever/never use data. Other studies of pesticide exposure and breast cancer incidence in the AHS cohort have not been conducted to date.

Bladder cancer. Applicators in the highest category of intensity-weighted imazethapyr exposure-days had an increased incidence of bladder cancer relative to nonexposed applicators, and a significant exposure-response pattern was observed (Koutros et al. 2009). Nine other pesticides were examined but were not associated with bladder cancer in pesticide applicators (alachlor, 
atrazine, carbaryl, dicamba, EPTC, glyphosate, malathion, permethrin, and trifluralin) (Bonner et al. 2007; De Roos et al. 2005a; Kang et al. 2008; Lee et al. 2004b; Mahajan et al. 2007; Rusiecki et al. 2004, 2009; Samanic et al. 2006; van Bemmel et al. 2008).

Prostate cancer. Applicators in the highest categories of fonofos exposure who also had a family history of prostate cancer had increased prostate cancer incidence relative to nonexposed applicators (Mahajan et al. 2006a). Significant exposure-response patterns were observed for both exposure measures, and the reported findings suggest that a family history of prostate cancer may modify prostate cancer risk in applicators exposed to fonofos. Applicators in the highest categories of fonofos exposure without a family history of prostate cancer did not have increased prostate cancer incidence $(\mathrm{RRLD}=0.86 ; 95 \% \mathrm{CI}$, 0.60-1.24; RRIWLD = 0.96; 95\% CI, 0.70-1.31). Applicators in the highest category of intensityweighted exposure-days for methyl bromide had increased prostate cancer risk relative to nonexposed applicators, and a significant exposure-response trend was observed (Alavanja et al. 2003). Twenty-three other pesticides were examined but were not associated with prostate cancer (alachlor, aldrin, atrazine, captan, carbofuran, carbaryl, chlorothalonil, chlorpyrifos, cyanazine, DDT, diazinon, dicamba, dichlorvos, EPTC, glyphosate, heptachlor, imazethapyr, malathion, metolachlor, pendimethalin, permethrin, phorate, and trifluralin) (Alavanja et al. 2003; Beane Freeman et al. 2005; Bonner et al. 2005, 2007; De Roos et al. 2005a; Greenburg et al. 2008; Hou et al. 2006; Kang et al. 2008; Koutros et al. 2008, 2009; Lynch et al. 2006; Mahajan et al. 2006b, 2007; Mozzachio et al. 2008; Rusiecki et al. 2004, 2006, 2009; Samanic et al. 2006; van Bemmel et al. 2008).

Brain cancer. Lee et al. (2004a) examined brain cancer incidence in pesticide applicators exposed to chlorpyrifos. Applicators in the highest category of intensity-weighted chlorpyrifos exposure-days had increased brain cancer incidence relative to nonexposed applicators, and a significant exposure-response pattern was observed. However, findings were based on small numbers of exposed cases $(2 \leq n \leq 7)$ and the exposure-response trend was not monotonic, as the second-highest exposure group had a lower risk of brain cancer $(\mathrm{RR}=1.25$; 95\% CI, 0.266.10) than applicators in the lowest category of exposure ( $R R=3.32$; 95\% CI, 0.98-11.24). Elevated RRs were reported for the two highest categories of chlorpyrifos exposure-days, but these estimates were not significantly increased and a significant exposure-response trend was not observed. Other studies of pesticide exposure and brain cancer incidence in the AHS cohort have not been conducted to date.

Melanoma. Applicators in the highest categories of lifetime carbaryl (Mahajan et al. 2007) and toxaphene (Purdue et al. 2006) exposure-days had an increased incidence of melanoma relative to nonexposed applicators. Significant exposureresponse patterns were not observed for carbaryl when exposures were analyzed according to lifetime exposure-days or intensity-weighted exposure-days (Mahajan et al. 2007). We observed a significant exposure-response trend with increasing LDs of toxaphene exposure but not when exposures were analyzed according to intensityweighted exposure-days. Ten other pesticides were examined but were not associated with melanoma incidence in pesticide applicators (atrazine, diazinon, dicamba, EPTC, fonofos, glyphosate, imazethapyr, malathion, pendimethalin, and permethrin) (Beane Freeman et al. 2005; Bonner et al. 2007; De Roos et al. 2005a; Hou et al. 2006; Koutros et al. 2009; Mahajan et al. 2006a; Rusiecki et al. 2004, 2009; Samanic et al. 2006; van Bemmel et al. 2008).

Other cancers. Kidney cancer. Six studies examined the relationship between pesticide exposure and kidney cancer in pesticide applicators, but strong associations were not observed for any of the pesticides examined (atrazine, chlorpyrifos, glyphosate, imazethapyr, malathion, and trifluralin) (Bonner et al. 2007; De Roos et al. 2005a; Kang et al. 2008; Koutros et al. 2009; Lee et al. 2004a; Rusiecki et al. 2004). Increased RRs were reported for applicators in the highest categories of trifluralin exposure relative to nonexposed applicators $(\mathrm{RRLD}=2.06$; 95\% CI, 0.75-5.65; RRIWLD $=1.77 ; 95 \%$ CI, 0.73-4.30), but these estimates were not significantly increased, and significant exposure-response trends were not observed for either exposure measure (Kang et al. 2008).

Childhood cancer. Flower et al. (2004) examined cancer incidence in children of male farmers in Iowa. Overall cancer incidence was increased among children of pesticide applicators (SIR = 1.36; 95\% CI, 1.03-1.79), and more lymphoma $(\mathrm{SIR}=2.18 ; 95 \% \mathrm{CI}, 1.13-4.19)$ and Hodgkin lymphoma (SIR $=2.56$; 95\% CI, 1.06-6.14) cases were observed than expected based on childhood cancer rates in the Iowa population. However, SIRs for specific cancers were based on small numbers of cases ( 2 d" n d" 11). Cancer risk was 
increased among children whose fathers did not use chemically resistant gloves when mixing pesticides relative to children with fathers who wore gloves $(\mathrm{OR}=1.98$; 95\% CI, 1.05-3.76). In addition, relative to children of nonexposed men, children whose fathers used aldrin during the prenatal period also had an increased cancer risk $(\mathrm{OR}=2.66$; 95\% CI, 1.08-6.59). Potential exposure-response patterns were not examined for specific pesticides, however, and 15 other pesticides examined in this study were not associated with childhood cancer (alachlor, atrazine, chlorpyrifos, cyanazine, 2,4-D, dichlorvos, dicamba, EPTC, glyphosate, malathion, metolachlor, metribuzin, phorate, trifluralin, and terbufos).

Miscellaneous. Several studies examined the relationship between pesticide exposures and oral cavity cancers (De Roos et al. 2005a; Koutros et al. 2009; Rusiecki et al. 2004, 2006), stomach cancer (Lee et al. 2004b), esophagus cancer (Lee et al. 2004a; Rusiecki et al. 2004), and thyroid cancer (Lee et al. 2004b), but none of the six pesticides examined were associated with increased risk of these types of cancers (alachlor, atrazine, chlorpyrifos, glyphosate, imazethapyr, and metolachlor).

\section{Discussion}

Through March 2009, 27 studies examined the relationship between LDs or IWLDs of pesticide exposure and cancer incidence in the AHS cohort. Thirty-two different pesticides were included in these studies, and most study participants personally applied pesticides for 11-30 years before enrollment (Alavanja et al. 2005). When appropriate, all studies adjusted for the use of pesticides correlated with the specific pesticide of interest; however, it is possible that this adjustment did not completely isolate the independent effects of each individual pesticide or eliminate the impact of multiple exposures. Nonetheless, findings from Coble et al. (2002) suggest that the magnitude of bias due to confounding from exposure to multiple agents is likely to be minimal based on the proportion of farmers reporting exposure to agents including cleaning solvents and diesel exhaust. Findings of chemical cohort analyses (i.e., studies of a single pesticide and multiple cancer types) and cancer site analyses (i.e., studies of a single cancer type and multiple pesticide exposures) were generally consistent with respect to the magnitude and direction of the observed associations. Specifically, chemical cohort and can- cer site analysis were consistent for carbaryl and colon cancer (no association) (Lee et al. 2007b; Mahajan et al. 2007), chlorpyrifos and rectal cancer (significantly increased risk) (Lee et al. 2004a, 2007b), pendimethalin, permethrin, and colorectal cancer (no association) (Hou et al. 2006; Lee et al. 2007b; Rusiecki et al. 2009), carbofuran, chlorpyrifos, diazinon, dieldrin, pendimethalin, and lung cancer (significantly increased risk) (Alavanja et al. 2004; Beane Freeman et al. 2005; Bonner et al. 2005; Hou et al. 2006; Lee et al. 2004a; Purdue et al. 2006), dicamba and lung cancer (no association with nonexposed reference group) (Alavanja et al. 2004; Samanic et al. 2006), atrazine, glyphosate, and pancreatic cancer (no association) (Andreotti et al. 2009; De Roos et al. 2005a; Rusiecki et al. 2004), and atrazine, captan, carbofuran, permethrin, and prostate cancer (no association) (Alavanja et al. 2003; Bonner et al. 2005; Greenburg et al. 2008; Rusiecki et al. 2004, 2009). Findings of Lee et al. (2007b) and Purdue et al. (2006) were somewhat inconsistent with respect to the relationship between chlordane and rectal cancer. Specifically, Purdue et al. (2006) reported an increased RR for applicators with $>9$ LDs of chlordane exposure, whereas Lee et al. (2007b) did not observe increased rectal cancer incidence among applicators with $>56$ days of exposure. However, in the analysis conducted by Lee et al. (2007b), only two exposed cases were available in the highest exposure group (> 56 LDs), and rectal cancer incidence was increased among applicators with 20-56 days of chlordane exposure. Therefore, both studies provide evidence of an association between chlordane and rectal cancer even though Lee et al. (2007b) did not observe an increased OR in the highest category of exposure. Chemical cohort analysis for metolachlor (Rusiecki et al. 2006) did not confirm the previously observed association with lung cancer (Alavanja et al. 2004). One explanation for this discrepancy may be that the association reported by Alavanja et al. (2004) occurred by chance, as findings were based on fewer exposed cases and were less precise. Alternatively, differences in cutoff points used for the highest exposure groups may explain this inconsistency; a value of 457 LDs was used by Alavanja et al. (2003), whereas a value of 116 LDs was used by Rusiecki et al. (2006). Therefore, it is possible that an increased RR was not reported by Rusiecki et al. (2006) because the highest exposure group included applicators with exposure levels below those likely to result in increased cancer risk. This possibility is supported by the fact that Alavanja et al. (2003) did not observe an association be- 
tween metolachlor and lung cancer among applicators exposed for 116-457 LDs. Finally, increased risks of colon cancer observed in chemical specific analyses for dicamba (Samanic et al. 2006) and trifluralin (Kang et al. 2008) do not agree with findings reported in cancer-specific analyses (Lee et al. 2007b). However, analyses for dicamba and trifluralin were limited to ever/never exposure classification in the study by Lee et al. (2007b), whereas Samanic et al. (2006) and Kang et al. (2008) reported increased RRs for colon cancer when exposures were analyzed according to intensityweighted exposure days. Therefore, differences in exposure classification may account for discrepancies observed between these studies.

In total, 19 pesticides were associated with a significantly increased risk of at least one type of cancer. Clear similarities by type (i.e., insecticide, herbicide, or fungicide), chemical structure, or chemical family were not apparent among these pesticides (Table 1). Seven of these 19 pesticides are no longer registered for use in Canada or the United States (chlordane, dieldrin, fonofos, heptachlor, lindane, methyl bromide, and toxaphene), and three additional pesticides, alachlor, aldicarb, and metolachlor, are registered for use in the United States but are not registered in Canada. Of the remaining pesticides currently registered for use in Canada or the United States, statistically significant exposure-response trends were observed for alachlor (all lymphohematopoietic), aldicarb (colon), carbaryl (melanoma), chlorpyrifos (lung, rectal), diazinon (all cancers, all lymphohematopoietic, leukemia, lung), dicamba (colon, lung), EPTC (all cancers, colon, pancreas), imazethapyr (bladder, colon), metolachlor (lung), pendimethalin (lung, pancreas, rectal), permethrin (multiple myeloma), and trifluralin (colon) (Alavanja et al.

Table 2. Evidence of carcinogenicity noted as of March 2009 by the U.S. EPA, PMRA, and IARC for registered pesticides that displayed a significant exposure-response relationship with at least one type of cancer.

\begin{tabular}{|c|c|c|c|c|c|}
\hline \multirow[b]{2}{*}{ Pesticide } & \multirow[b]{2}{*}{ Type } & \multirow[b]{2}{*}{$\begin{array}{l}\text { Cancer type(s) with } \\
\text { exposure-responsein } \\
\text { the AHS cohort }\end{array}$} & \multicolumn{3}{|c|}{ Organization } \\
\hline & & & U.S. EPA & PMRA & IARC \\
\hline Alachlor (Lee et al. 2004b) & Herbicide & All LH & $\begin{array}{l}\text { Likely (high } \\
\text { doses)/not likely } \\
\text { (low doses) }\end{array}$ & $\begin{array}{l}\text { Not registered in } \\
\text { Canada }\end{array}$ & Not evaluated \\
\hline Aldicarb (Lee et al. 2007a) & Insecticide & Colon & Group $\mathrm{E}^{a}$ & $\begin{array}{l}\text { Not registered in } \\
\text { Canada }\end{array}$ & Group $3^{b}$ \\
\hline $\begin{array}{l}\text { Carbaryl (Mahajan et al. } \\
\text { 2007) }\end{array}$ & Insecticide & Melanoma & Likely & $\begin{array}{l}\text { Under re-evaluation } \\
\text { (positive) }^{c}\end{array}$ & Group $3^{b}$ \\
\hline $\begin{array}{l}\text { Chlorpyrifos (Lee et al. 2004a, } \\
2007 \mathrm{~b}\end{array}$ & Insecticide & Lung, rectum & Group $E^{a}$ & Negative $^{d}$ & Not evaluated \\
\hline $\begin{array}{l}\text { Diazinon (Alavanja et al. } \\
\text { 2004; Beane Freeman et al. } \\
\text { 2005) }\end{array}$ & Insecticide & $\begin{array}{l}\text { All cancers, all LH, } \\
\text { leukemia, lung }\end{array}$ & Not likely & Negative $^{d}$ & Not evaluated \\
\hline $\begin{array}{l}\text { Dicamba (Alavanja et al. } \\
\text { 2004; Samanic et al. 2006) }\end{array}$ & Herbicide & Colon, lung & Not likely & Negative $^{d}$ & Not evaluated \\
\hline $\begin{array}{l}\text { EPTC (Andreotti et al. 2009; } \\
\text { van Bemmel et al. 2008) }\end{array}$ & Herbicide & $\begin{array}{l}\text { All cancers, colon, } \\
\text { leukemia, páncreas }\end{array}$ & Not likely & Negative $^{d}$ & Not evaluated \\
\hline $\begin{array}{l}\text { Imazethapyr (Koutros et al. } \\
\text { 2009) }\end{array}$ & Herbicide & Bladder, colon & Not likely & $\begin{array}{l}\text { Under re-evaluation } \\
\text { (negative) }^{d}\end{array}$ & Not evaluated \\
\hline $\begin{array}{l}\text { Metolachlor (Alavanja et al. } \\
\text { 2004) }\end{array}$ & Herbicide & Lung & Group $\mathrm{C}^{e}$ & $\begin{array}{l}\text { Not registered in } \\
\text { Canada }\end{array}$ & Not evaluated \\
\hline $\begin{array}{l}\text { Pendimethalin (Alavanja et al. } \\
\text { 2004; Andreotti et al. 2009; } \\
\text { Hou et al. 2006) }\end{array}$ & Herbicide & $\begin{array}{l}\text { Lung, rectum, } \\
\text { pancreas }\end{array}$ & Group $\mathrm{C}^{e}$ & Positive $^{c}$ & Not evaluated \\
\hline $\begin{array}{l}\text { Permethrin (Rusiecki et al. } \\
\text { 2006, 2009) }\end{array}$ & Insecticide & Myeloma & Likely & Positive $^{c}$ & Group $3^{b}$ \\
\hline Trifluralin (Kang et al. 2008) & Herbicide & Colon & Group $C^{e}$ & Positive $^{c}$ & Not evaluated \\
\hline
\end{tabular}

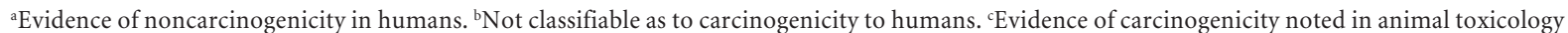
database. ${ }^{\mathrm{d}}$ No evidence of carcinogenicity in animal toxicology database. ${ }^{\mathrm{e}} \mathrm{P}$ ossible human carcinogen. 
2004; Andreotti et al. 2009; Beane Freeman et al. 2005; Hou et al. 2006; Kang et al. 2008; Koutros et al. 2009; Lee et al. 2004a, 2004b, 2007b; Mahajan et al. 2007; Rusiecki et al. 2006, 2009; Samanic et al. 2006; van Bemmel et al. 2008). These pesticides are listed in Table 2 along with animal toxicologic evidence of carcinogenicity noted by the U.S. EPA (2007), Canadian Pest Management Regulatory Agency (PMRA) (Health Canada 2003, 2005, 2007, 2008), and the International Agency for Research on Cancer (IARC 2010). The U.S. EPA classification terms "likely" and "not likely" in Table 2 do not correspond to quantifiable probabilities of carcinogenicity but instead reflect the weight of animal toxicologic evidence for or against such a relationship (i.e., a classification of "likely" does not mean that a given pesticide is a confirmed carcinogen, but only that such an effect is plausible give current toxicologic evidence).

The IARC has not evaluated most pesticides listed in Table 2 (alachlor, chlorpyrifos, diazinon, dicamba, EPTC, imazethapyr, metolachlor, pendimethalin, and trifluralin) and considers the remaining pesticides (aldicarb, carbaryl, and permethrin) not classifiable with respect to human carcinogenicity (group 3). Evidence of carcinogenicity was noted by the U.S. EPA and/or PMRA in animal toxicity studies for alachlor, carbaryl, metolachlor, pendimethalin, permethrin, and trifluralin, thus supporting the biological plausibility of associations observed for these pesticides. The remaining registered pesticides for which exposure-response relationships were observed are not considered carcinogenic by the U.S. EPA or PMRA (aldicarb, chlorpyrifos, diazinon, dicamba, EPTC, and imazethapyr).

Risk estimates were imprecise for most registered pesticides that displayed an exposure-response pattern with at least one type of cancer because of small numbers of exposed cases. Specifically, d" 12 cases were available in the highest categories of exposure for aldicarb (colon), carbaryl (melanoma), chlorpyrifos (rectal), diazinon (all LH, leukemia, lung), dicamba (lung), EPTC (pancreas), imazethapyr (colon, bladder), metolachlor (lung), pendimethalin (lung, pancreas, rectal), and permethrin (multiple myeloma). As a result, little can be concluded at this time regarding the causal nature of these associations, and further analyses are required once more cases have accrued. RRs for chlorpyrifos and lung cancer and EPTC and colon cancer were more precise, each indicating that cancer incidence doubled in the highest exposure groups relative to nonexposed applicators (Lee et al. 2004a; van
Bemmel et al. 2008). However, the weight of biological evidence reviewed by the U.S. EPA and PMRA does not suggest that chlorpyrifos and EPTC are carcinogenic (Health Canada 2003, 2008; Smegal 2002; U.S. EPA 1999). One explanation for discrepancies between AHS findings and toxicologic evidence may be that animal toxicity tests typically reflect exposure to a single pesticide active ingredient and not the end-use product or multiple products. Therefore, real-life exposures in the field are not equivalent to what is tested in animal toxicity studies. Alternatively, some AHS findings may have occurred by chance because of the large number of multiple comparisons or bias from uncontrolled confounding or other source of bias. Nevertheless, as many of the studies reviewed are the first to examine the reported associations, the findings are useful for generating hypotheses that require confirmation in future studies. Going forward, adjustment for multiple comparisons will be important to avoid spurious associations. Likewise, bias analysis may be helpful in characterizing overall uncertainty in AHS findings; a recent study by Lash (2007) illustrates how conventional frequentist methods may understate uncertainty in effect measures by quantifying only random error and may result in bias away from the null.

Epidemiologic evidence outside the AHS cohort remains limited with respect to associations observed for specific pesticides and cancer types listed in Table 2. Three studies examined cancer incidence in a cohort of alachlor manufacturing workers in Iowa (Acquavella et al. 1996, 2004; Leet et al. 1996). Lymphohematopoietic tumors were increased in one of these studies relative to expected values in the Iowa population (SIR = 3.6; 95\% CI, 1.2-8.5) (Leet et al. 1996); however, this estimate was based on only five exposed cases, and potential confounding factors were not included in the analyses. Two or fewer lymphohematopoietic cancer cases were available in studies conducted by Acquavella et al. (1996, 2004), and in general, none of the three studies of alachlor manufacturing workers provides strong evidence of an important relationship between alachlor and cancer. Studies of carbaryl and melanoma have not been conducted outside the AHS cohort, but Zheng et al. (2001) reported an association between small-cell lymphoma among participants exposed to carbaryl in a pooled analysis of three case-control studies in the United States (Cantor et al. 1992; Hoar et al. 1986; Zahm et al. 1990). However, carbaryl exposure was not associated with NHL in a Canadian case-control 
study after adjusting for a number of potential confounding factors (McDuffie et al. 2001), and carbaryl was not associated with NHL in the AHS cohort (Mahajan et al. 2007). A case-control study examined lung cancer mortality in Florida pest control workers exposed to chlorpyrifos and diazinon, but neither pesticide was associated with a significantly increased risk of lung cancer mortality (Pesatori et al. 1994). Chlorpyrifos and diazinon were identified as possible risk factors for NHL in a pooled analysis of three case-control studies in Iowa, Minnesota, Kansas, and Nebraska (Waddell et al. 2001); however, these pesticides were not associated with NHL in the AHS cohort (Beane Freeman et al. 2005; Lee et al. 2004a). One previous case-control study observed an association between dicamba and NHL (McDuffie et al. 2001), but dicamba was not associated with NHL in the AHS cohort. Hoar et al. (1986) noted an association between NHL and trifluralin exposure based on only three exposed cases, but a more recent pooled analysis did not observe a significant relationship between trifluralin and NHL (De Roos et al. 2003). Previous studies of chlorpyrifos and rectal cancer and diazinon and leukemia were not identified. Likewise, studies of aldicarb, dicamba, and colon cancer, EPTC and colon or pancreatic cancer, imazethapyr and bladder or colon cancer, metolachlor and lung cancer, pendimethalin and lung, rectal, or pancreatic cancer, permethrin and myeloma, and trifluralin and colon cancer were not identified outside the AHS cohort, and epidemiologic evidence in general is limited for these pesticides.

Exposure assessment is a challenge in largescale epidemiologic studies, as it is often not possible to obtain quantitative exposure data at etiologically relevant time periods for large numbers of study participants. In the AHS, self-reported LDs and IWLDs of pesticide exposure are used as the primary exposure measures. To date, four studies have examined the validity of the intensityweighted exposure algorithm used in the AHS (Acquavella et al. 2006; Coble et al. 2005; Thomas et al. 2009). Two of these studies were conducted using data from the Pesticide Exposure Assessment Study conducted in Canada (Acquavella et al. 2006; Coble et al. 2005), and the remaining two studies were conducted using members of the AHS cohort (Hines et al. 2008; Thomas et al. 2009). In general, validation studies have observed low to moderate correlations between exposure intensity algorithm scores and urinary biomarkers of 2,4-D, 4-chloro-2-methylphenoxyacetic acid (MCPA), captan, glyphosate, and chlorpyrifos
(Acquavella et al. 2006; Coble et al. 2005; Hines et al. 2008; Thomas et al. 2009). Low to moderate correlations were also reported between algorithm scores and quantitative levels of 2,4-D and chlorpyrifos measured in hand-wipe samples, dermal patches, and personal air samples (Thomas et al. 2009); however, correlations between algorithm scores and quantitative measures of chlorpyrifos exposure varied by application method, with stronger correlations observed for liquid spray applications relative to granular in-furrow applications. For captan, intensity-weighted algorithm scores were predictive of exposure levels measured on dermal patch samples located on the thighs of pesticide applicators but were not significant predictors of captan levels measured in personal air samples, hand rinses, and forearm patches (Hines et al. 2008). Weighted kappa values for categorical agreement between algorithm scores and biomarker levels were low to moderate $(0.07<$ kappa $<$ $0.37)$ in validation studies conducted to date, and considerable overlap in urinary biomarker levels was apparent between exposure categories based on algorithm scores (Acquavella et al. 2006; Thomas et al. 2009). However, algorithm scores were able to detect significant trends in urine and handwipe concentrations of 2,4-D (Coble et al. 2005; Thomas et al. 2009) and urine concentrations of MCPA (Coble et al. 2005), and in general, biomarker levels tended to be greatest among participants labeled as having the highest exposures (Acquavella et al. 2006; Thomas et al. 2009).

Exposure misclassification undoubtedly had an impact on AHS findings reported to date. As participants reported exposures prior to disease onset, the process of exposure misclassification in the AHS cohort is likely to be nondifferential; however, this does not guarantee bias toward the null in any individual study (Dosemeci et al. 1990; Jurek et al. 2005; 2008; Pearce et al. 2007; Sorahan and Gilthorpe 1994; Thomas 1995). What seems apparent from validation studies is that the exposure intensity algorithm is capable of differentiating subjects with the highest and lowest exposure levels but is less capable of valid exposure classification across an exposure gradient. Unfortunately, this limits the ability to detect exposure-response patterns, as substantial exposure misclassification is expected to occur across categories of exposure. Further validation of the exposure intensity algorithm in biomonitoring studies for an expanded group of pesticides may help to characterize this uncertainty. Similarly, the applicability of intensity-weighted exposure measures in studies of lung cancer requires further 
evaluation, as the algorithm weighs dermal exposures most heavily (Dosemeci et al. 2002) and may not offer an improvement over lifetime-exposure days for outcomes related to inhalation exposures. Finally, it is not clear how current exposure levels compare with those during etiologically relevant time periods, as the first years of pesticide use often occurred decades prior to enrollment in the AHS.

\section{Conclusions}

We reviewed 28 studies of pesticide exposure and cancer incidence in the AHS cohort. Most of the 32 pesticides examined were not strongly associated with cancer, but increased RRs/ORs and positive exposure-response relationships were observed for 12 pesticides currently registered in Canada and/or the United States. However, RRs and ORs were often imprecise because of small numbers of exposed cases, and further followup is required once more cases have accrued.
Epidemiologic evidence outside the AHS cohort remains limited with respect to most of the observed associations, but animal toxicity data support the possible carcinogenicity of alachlor, carbaryl, metolachlor, pendimethalin, permethrin, and trifluralin. Although the exposure intensity algorithm developed for the AHS offers an improvement over ever/never exposure classification often employed in environmental health studies, exposure misclassification remains a concern. In particular, analysis of exposure-response trends is limited by expected exposure misclassification across categories of LDs and IWLDs. Further validation of the exposure intensity algorithm for an expanded group of pesticides will help to characterize uncertainty resulting from exposure misclassification. In addition, continued follow-up of the AHS cohort as a whole will help to clarify associations reported to date. In doing so, particular attention should be paid to registered pesticides that displayed evidence of a possible association with cancer.

\section{References}

Acquavella JF, Alexander BH, Mandel JS, Burns CJ, Gustin C. 2006. Exposure misclassification in studies of agricultural pesticides: insights from biomonitoring. Epidemiology 17:69-74.

Acquavella JF, Delzell E, Cheng H, Lynch CF, Johnson G. 2004. Mortality and cancer incidence among alachlor manufacturing workers 1968-99. Occup Environ Med 61:680-685.

Acquavella JF, Riordan SG, Anne M, Lynch CF, Collins JJ, Ireland BK, et al. 1996. Evaluation of mortality and cancer incidence among alachlor manufacturing workers. Environ Health Perspect 104:728-733.

Agricultural Health Study. 2009. Agricultural Health Study Homepage. Available: http:// aghealth.nci.nih.gov [accessed 1 March 2009].

Alavanja MCR, Dosemeci M, Samanic C, Lubin J, Lynch CF, Knott C, et al. 2004. Pesticides and lung cancer risk in the Agricultural Health Study cohort. Am J Epidemiol 160:876-885.

Alavanja MCR, Samanic C, Dosemeci M, Lubin J, Tarone R, Lynch CF, et al. 2003. Use of agricultural pesticides and prostate cancer in the Agricultural Health Study cohort. Am J Epidemiol 157:800-814.

Alavanja MCR, Sandler DP, Lynch CF, Knott C, Lubin JH, Tarone R, et al. 2005. Cancer incidence in the Agricultural Health Study. Scand J Work Environ Health 31(suppl 1):39-45.
Alavanja MCR, Sandler DP, McMaster SB, Zahm SH, McDonnell CJ, Lynch CF, et al. 1996. The Agricultural Health Study. Environ Health Perspect 104:362369.

Andreotti G, Beane-Freeman L, Hou L, Coble J, Rusiecki J, Hoppin JA, et al. 2009. Agricultural pesticide use and pancreatic cancer risk in the Agricultural Health Study cohort. Int J Cancer 124:2495-2500.

Beane Freeman LE, Bonner MR, Blair A, Hoppin JA, Sandler DP, Lubin JH, et al. 2005. Cancer incidence among male pesticide applicators in the Agricultural Health Study cohort exposed to diazinon. Am J Epidemiol 162:1070-1079.

Beseler C, Stallones L, Hoppin JA, Alavanja MCR, Blair A, Keefe T, et al. 2006. Depression and pesticide exposures in female spouses of licensed pesticide applicators in the Agricultural Health Study cohort. J Occup Environ Med 48:1005-1013.

Beseler CL, Stallones L, Hoppin JA, Alavanja MCR, Blair A, Keefe T, et al. 2008. Depression and pesticide exposure among private pesticide applicators enrolled in the Agricultural Health Study. Environ Health Perspect 116:1713-1719.

Blair A, Sandler D, Tarone R, Lubin J, Thomas K, Hoppin JA, et al. 2005a. Mortality among participants in the Agricultural Health Study. Ann Epidemiol 15:279-285. 
Blair A, Sandler D, Thomas K, Hoppin JA, Kamel F, Coble J, et al. 2005b. Disease and injury among participants in the Agricultural Health Study. $J$ Agric Saf Health 11:141-150.

Blair A, Tarone R, Sandler D, Lynch CF, Rowland A, Wintersteen W, et al. 2002. Reliability of reporting on life-style and agricultural factors by a sample of participants in the Agricultural Health Study from Iowa. Epidemiology 13:94-99.

Bonner MR, Coble J, Blair A, Beane-Freeman L, Hoppin JA, Sandler DP, et al. 2007. Malathion exposure and the incidence of cancer in the Agricultural Health Study. Am J Epidemiol 166:1023-1034.

Bonner MR, Lee WJ, Sandler DP, Hoppin JA, Dosemeci M, Alavanja MCR. 2005. Occupational exposure to carbofuran and the incidence of cancer in the Agricultural Health Study. Environ Health Perspect 113:285-289.

Cantor KP, Blair A, Everett G, Gibson R, Burmeister LF, Brown LM, et al. 1992. Pesticides and other agricul tural risk factors for non-Hodgkin's lymphoma among men in Iowa and Minnesota. Cancer Res 52:2447-2455.

Coble J, Arbuckle T, Lee W, Alavanja M, Dosemeci M. 2005. The validation of a pesticide exposure algorithm using biological monitoring results. J Occup Environ Hyg 2:194-201.

Coble J, Hoppin JA, Engel L, Elci OC, Dosemeci M, Lynch CF, et al. 2002. Prevalence of exposure to solvents, metals, grain dust, and other hazards among farmers in the Agricultural Health Study. $J$ Expo Anal Environ Epidemiol 12:418-426.

Cooper GS, Martin SA, Longnecker MP, Sandler DP, Germolec DR. 2004. Associations between plasma DDE levels and immunologic measures in AfricanAmerican farmers in North Carolina. Environ Health Perspect 112:1080-1084.

Crawford JM, Hoppin JA, Alavanja MCR, Blair A, Sandler DP, Kamel F. 2008. Hearing loss among licensed pesticide applicators in the Agricultura Health Study. J Occup Environ Med 50:817-826.

De Roos AJ, Blair A, Rusiecki JA, Hoppin JA, Svec M, Dosemeci M, et al. 2005a. Cancer incidence among glyphosate-exposed pesticide applicators in the Agricultural Health Study. Environ Health Perspect 113:49-54.

De Roos AJ, Cooper GS, Alavanja MC, Sandler DP 2005b. Rheumatoid arthritis among women in the Agricultural Health Study: risk associated with farming activities and exposures. Ann Epidemiol 15:762770

De Roos AJ, Zahm SH, Cantor KP, Weisenberg DD, Holmes FF, Burnmeister LF, et al. 2003. Integrative assessment of multiple pesticides as risk factors for non-Hodgkin's lymphoma among men. Occup Environ Med 60:E11; doi: 10.1136/oem.60.9.e11 [Online September 2003].

Dosemeci M, Alavanja MCR, Rowland AS, Mage D, Zahm SH, Rothman N, et al. 2002. A quantitative approach for estimating exposure to pesticides in the Agricultural Health Study. Ann Occup Hyg 46:245-260

Dosemeci M, Wacholder S, Lubin JH. 1990. Does nondifferential misclassification of exposure always bias a true effect toward the null value? Am J Epidemiol 132:746-748
Engel LS, Hill DA, Hoppin JA, Lubin JH, Lynch CF, Pierce J, et al. 2005. Pesticide use and breast cancer risk among farmers' wives in the Agricultural Health Study. Am J Epidemiol 161:121-135.

Farr SL, Cai J, Savitz DA, Sandler DP, Hoppin JA, Cooper GS. 2006. Pesticide exposure and the timing of menopause. Am J Epidemiol 163:731-742.

Farr SL, Cooper GS, Cai J, Savitz DA, Sandler DP. 2004. Pesticide use and menstrual cycle characteristics among premenopausal women in the Agricultural Health Study. Am J Epidemiol 160:1194-1204.

Flower KB, Hoppin JA, Lynch CF, Blair A, Knott C, Shore DL, et al. 2004. Cancer risk and parental pesticide application in children of Agricultural Health Study participants. Environ Health Perspect 112:631635.

Greenburg DL, Rusiecki J, Koutros S, Dosemeci M, Patel R, Hines CJ, et al. 2008. Cancer incidence among pesticide applicators exposed to captan in the Agricultural Health Study. Cancer Causes Control 19:1401-1407.

Health Canada. 2003. Proposed Acceptability for Continuing Registration: Phase 2 of the Re-evaluation of Chlorpyrifos. Catalog No. H113-18/2003-3E-IN. Ottawa, Ontario, Canada:Pest Management Regulatory Agency.

Health Canada. 2005. Re-evaluation Note: Preliminary Risk and Value Assessments of Diazinon. Catalog No. H113-5/2005-6E. Ottawa, Ontario, Canada:Pest Management Regulatory Agency.

Health Canada. 2007. Re-evaluation Decision: Pendimethalin. Catalog No. H113-27/2007-7E. Ottawa, Ontario, Canada: Pest Management Regulatory Agency.

Health Canada. 2008. Re-evaluation Decision: S-ethyl dipropylthiocarbamate (EPTC). Catalog No. H11328/2008-6E. Ottawa, Ontario, Canada:Pest Management Regulatory Agency.

Hines CJ, Deddens JA, Jaycox LB, Andrews RN, Striley CA, Alavanja MC. 2008. Captan exposure and evaluation of a pesticide exposure algorithm among orchard pesticide applicators in the Agricultural Health Study. Ann Occup Hyg 52:153-166.

Hoar SK, Blair A, Holmes FF, Boysen CD, Robel RJ, Hoover R, et al. 1986. Agricultural herbicide use and risk of lymphoma and soft-tissue sarcoma. JAMA 256:1141-1147.

Hoppin JA, Umbach DM, Kullman GJ, Henneberger PK, London SJ, Alavanja MCR, et al. 2007a. Pesticides and other agricultural factors associated with self-reported farmer's lung among farm residents in the Agricultural Health Study. Occup Environ Med 64:334-342.

Hoppin JA, Umbach DM, London SJ, Alavanja MCR, Sandler DP. 2002a. Chemical predictors of wheeze among farmer pesticide applicators in the Agricultural Health Study. Am J Respir Crit Care Med 165:683-689.

Hoppin JA, Umbach DM, London SJ, Henneberger PK, Kullman GJ, Alavanja MCR, et al. 2008. Pesticides and atopic and nonatopic asthma among farm women in the Agricultural Health Study. Am J Respir Crit Care Med 177:11-18.

Hoppin JA, Umbach DM, London SJ, Lynch CF, Alavanja MCR, Sandler DP. 2006a. Pesticides associated with wheeze among commercial pesticide applicators in the Agricultural Health Study. Am J Epidemiol 163:1129-1137. 
Hoppin JA, Umbach DM, London SJ, Lynch CF, Alavanja MCR, Sandler DP. 2006b. Pesticides and adult respiratory outcomes in the Agricultural Health Study. Ann NY Acad Sci 1076:343-354.

Hoppin JA, Valcin M, Henneberger PK, Kullman GJ, Umbach DM, London SJ, et al. 2007b. Pesticide use and chronic bronchitis among farmers in the Agricultural Health Study. Am J Ind Med 50:969-979.

Hoppin JA, Yucel F, Dosemeci M, Sandler DP. 2002b. Accuracy of self-reported pesticide use duration information from licensed pesticide applicators in the Agricultural Health Study. J Expo Anal Environ Epidemiol 12:313-318.

Hou L, Lee WJ, Rusiecki J, Hoppin JA, Blair A, Bonner MR, et al. 2006. Pendimethalin exposure and cancer incidence among pesticide applicators. Epidemiology 17:302-307.

IARC (International Agency for Research on Cancer). 2010. IARC Monographs on the Evaluation of Carcinogenic Risks to Humans. Available: http:// www.iarc.fr/en/publications/list/monographs [accessed 1 January 2010].

Jurek AM, Greenland S, Maldonado G. 2008. How far from non-differential does exposure or disease misclassification have to be to bias measures of association away from the null? Int J Epidemiol 37:382385.

Jurek AM, Greenland S, Maldonado G, Church TR. 2005. Proper interpretation of non-differential misclassification effects: expectation vs observations. Int J Epidemiol 34:680-687.

Kamel F, Boyes WK, Gladen BC, Rowland AS, Alavanja MCR, Blair A, et al. 2000. Retinal degeneration in licensed pesticide applicators. Am J Ind Med 37:618628.

Kamel F, Engel LS, Gladen BC, Hoppin JA, Alavanja MCR, Sandler DR. 2005. Neurologic symptoms in licensed private pesticide applicators in the Agricultural Health Study. Environ Health Perspect 113:877-882.

Kamel F, Engel LS, Gladen BC, Hoppin JA, Alavanja MCR, Sandler DR. 2007a. Neurologic symptoms in licensed pesticide applicators in the Agricultural Health Study. Hum Exp Toxicol 26:243-250.

Kamel F, Tanner CM, Umbach DM, Hoppin JA, Alavanja MCR, Blair A, et al. 2007b. Pesticide exposure and self-reported Parkinson's disease in the Agricultural Health Study. Am J Epidemiol 165:364374.

Kang D, Park SK, Beane-Freeman L, Lynch CF, Knott CE, Sandler DP, et al. 2008. Cancer incidence among pesticide applicators exposed to trifluralin in the Agricultural Health Study. Environ Res 107:271-276.

Kirrane EF, Hoppin JA, Kamel F, Umbach DM, Boyes WK, DeRoos AJ, et al. 2005. Retinal degeneration and other eye disorders in wives of farmer pesticide applicators enrolled in the Agricultural Health Study. Am J Epidemiol 161:1020-1029.

Koutros S, Lynch CF, Ma X, Lee WJ, Hoppin JA, Christensen $\mathrm{CH}$, et al. 2009. Heterocyclic aromatic amine pesticide use and human cancer risk: results from the U.S. Agricultural Health Study. Int J Cancer 124:1206-1212.

Koutros S, Mahajan R, Zheng T, Hoppin JA, Ma X, Lynch CF, et al. 2008. Dichlorvos exposure and human cancer risk: results from the Agricultural Health Study. Cancer Causes Control 19:59-65.
Lash TL. 2007. Bias analysis applied to Agricultural Health Study publications to estimate non-random sources of uncertainty. J Occup Med Toxicol 2:1523.

Lee WJ, Alavanja MCR, Hoppin JA, Rusiecki JA, Kamel F, Blair A, et al. 2007a. Mortality among pesticide applicators exposed to chlorpyrifos in the Agricultural Health Study. Environ Health Perspect 115:528534 .

Lee WJ, Blair A, Hoppin JA, Lubin JH, Rusiecki JA, Sandler DP, et al. 2004a. Cancer incidence among pesticide applicators exposed to chlorpyrifos in the Agricultural Health Study. J Natl Cancer Inst 96:17811791.

Lee WJ, Hoppin JA, Blair A, Lubin JH, Dosemeci M, Sandler DP, et al. 2004b. Cancer incidence among pesticide applicators exposed to alachlor in the Agricultural Health Study. Am J Epidemiol 159:373380.

Lee WJ, Sandler DP, Blair A, Samanic C, Cross AJ, Alavanja MCR. 2007b. Pesticide use and colorectal cancer risk in the Agricultural Health Study. In J Cancer 121:339-346.

Leet T, Acquavella J, Lynch C, Anne M, Weiss NS, Vaughan T, et al. 1996. Cancer incidence among alachlor manufacturing workers. Am J Ind Med 30:300-306.

Litchfield MH. 1999. Agricultural work related injury and ill-health and the economic cost. Environ Sci Pollut Res 6:175-182.

Lynch SM, Rusiecki JA, Blair A, Dosemeci M, Lubin J, Sandler D, et al. 2006. Cancer incidence among pesticide applicators exposed to cyanazine in the Agricultural Health Study. Environ Health Perspect 114:1248-1252.

Mahajan R, Blair A, Coble J, Lynch CF, Hoppin JA, Sandler DP, et al. 2007. Carbaryl exposure and incident cancer in the Agricultural Health Study. Int $J$ Cancer 121:1799-1805.

Mahajan R, Blair A, Lynch CF, Schroeder P, Hoppin JA, Sandler DP, et al. 2006a. Fonofos exposure and cancer incidence in the Agricultural Health Study. Environ Health Perspect 114:1838-1842.

Mahajan R, Bonner MR, Hoppin JA, Alavanja MCR. 2006b. Phorate exposure and incidence of cancer in the Agricultural Health Study. Environ Health Perspect 114:1205-1209.

Martin SA, Harlow SD, Sowers MF, Longnecker MP, Garabrant D, Shore DL, et al. 2002. DDT metabolite and androgens in African-American farmers. Epidemiology 13:454-458.

McDuffie HH, Pahwa P, McLaughlin JR, Spinelli JJ, Finchman S, Dosman JA, et al. 2001. NonHodgkin's lymphoma and specific pesticide exposures in men: cross-Canada study of pesticides and health. Cancer Epidemiol Biomarkers Prev 10:11551163 .

Montgomery MP, Kamel F, Saldana TM, Alavanja MCR, Sandler DP. 2008. Incident diabetes and pesticide exposure among licensed pesticide applicators: Agricultural Health Study, 1993-2003. Am J Epidemiol 167:1235-1246.

Mozzachio AM, Rusiecki JA, Hoppin JA, Mahajan R, Patel R, Beane-Freeman L, et al. 2008. Chlorothalonil exposure and cancer incidence among pesticide applicator participants in the Agricultural Health Study. Environ Res 108:400-403. 
Pearce N, Checkoway H, Kriebel D. 2007. Bias in occupational epidemiology studies. Occup Environ Med 64:562-568.

Pesatori AC, Sontag JM, Lubin JH, Consonni D, Blair A. 1994. Cohort mortality and nested case-control study of lung cancer among structural pest control workers in Florida (United States). Cancer Causes Control 5:310-318.

Popendorf W, Donham KJ. 1991. Agricultural hygiene. In: Patty's Industrial Hygiene and Toxicology, 4th ed, Vol 1, Pt A. New York:John Wiley \& Sons, 721-761.

Purdue MP, Hoppin JA, Blair A, Dosemeci M, Alavanja MCR. 2006. Occupational exposure to organochlorine insecticides and cancer incidence in the Agricultural Health Study. Int J Cancer 120:642-649.

Rusiecki JA, De Roos A, Lee WJ, Dosemeci M, Lubin JH, Hoppin JA, et al. 2004. Cancer incidence among pesticide applicators exposed to atrazine in the Agricultural Health Study. J Natl Cancer Inst 96:13751382.

Rusiecki JA, Hou L, Lee WJ, Blair A, Dosemeci M, Lubin JH, et al. 2006. Cancer incidence among pesticide applicators exposed to metolachlor in the Agricultural Health Study. Int J Cancer 118:31183123.

Rusiecki JA, Patel R, Koutros S, Beane-Freeman L, Landgren O, et al. 2009. Cancer incidence among pesticide applicators exposed to permethrin in the Agricultural Health Study. Environ Health Perspect 117:581-586.

Saldana TM, Basso O, Hoppin JA, Baird DD, Knott C, Blair A, et al. 2007. Pesticide exposure and selfreported gestational diabetes mellitus in the Agricultural Health Study. Diabetes Care 30:529-534.

Samanic C, Rusiecki J, Dosemeci M, Hou L, Hoppin JA, Sandler DP, et al. 2006. Cancer incidence among pesticide applicators exposed to dicamba in the Agricultural Health Study. Environ Health Perspect 114:1521-1526.

Shaver CS, Tong T. 1991. Chemical hazards to agricultural workers. Occup Med State Art Review 6:391413.

Smegal DC. 2002. Human Health Risk AssessmentChlorpyrifos. Washington, DC:U.S. Environmental Protection Agency. Sorahan T, Gilthorpe MS. 1994. Non-differential misclassification of exposure always leads to an underestimate of risk: an incorrect conclusion. Occup Environ Med 51:839-840.

Sprince NL, Park H, Zwerling C, Lynch CF, Whitten PA, Thu K, et al. 2002. Risk factors for machineryrelated injury among Iowa livestock farmers: a casecontrol study nested in the Agricultural Health Study. Int J Occup Environ Health 8:332-338.

Sprince NL, Park H, Zwerling C, Lynch CF, Whitten PS, Thu K, et al. 2003a. Risk factors for animal-related injury among Iowa livestock farmers: a case-control study nested in the Agricultural Health Study. $J$ Rural Health 19:165-173.

Sprince NL, Park H, Zwerling C, Whitten PA, Lynch CF, Burmeister LF, et al. 2007. Risk factors for low back injury among farmers in Iowa: a case-control study nested in the Agricultural Health Study. J Occup Environ Hyg 4:10-16.

Sprince NL, Zwerling C, Lynch CF, Whitten PA, Thu K, Gillette PP, et al. 2003b. Risk factors for falls among Iowa farmers: a case-control study nested in the Agricultural Health Study. Am J Ind Med 44:265272
Sprince NL, Zwerling C, Lynch CF, Whitten PS, Thu K, Logsden-Sackett N, et al. 2003c. Risk factors for agricultural injury: a case-control analysis of Iowa farmers in the Agricultural Health Study. J Agric Saf Health 9:5-18.

Tarone RE, Alavanja MCR, Zahm SH, Lubin JH, Sandler DP, McMaster SB, et al. 1997. The Agricultural Health Study: factors affecting completion and return of self-administered

questionnaires in a large prospective cohort study of pesticide applicators. Am J Ind Med 31:233-242.

Thomas D. 1995. When will nondifferential misclassification of an exposure preserve the direction of trend? Am J Epidemiol 142:782-783.

Thomas KW, Dosemeci M, Coble JB, Hoppin JA, Sheldon LS, Chapa G, et al. 2009. Assessment of a pesticide exposure intensity algorithm in the Agricultural Health Study. J Expo Sci Environ Epidemiol; doi:10.1038/jes.2009.54 [Online 4 November 2009].

U.S. EPA. 1999. Reregistration Eligibility Decision: EPTC. EPA/738/R/99/006. Washington, DC:

U.S. Environmental Protection Agency.U.S. EPA (U.S. Environmental Protection Agency). 2007. List of Chemicals Evaluated for Carcinogenic Potential. Available: http://www.epa.gov/pesticides/carlist [accessed 1 March 2009].

U.S. EPA. 2009. Reregistration Eligibility Decision: Permethrin. EPA/738/R/09/306. Washington, DC:U.S. Environmental Protection Agency.

Valcin M, Henneberger PK, Kullman GJ, Umbach DM, London SJ, Alavanja MCR, et al. 2007. Chronic bronchitis among nonsmoking farm women in the Agricultural Health Study. J Occup Environ Med 49:574-583.

van Bemmel DM, Visvanathan K, Beane-Freeman LE, Coble J, Hoppin J, Alavanja MCR. 2008. S-ethyl$\mathrm{N}, \mathrm{N}$-dipropylthiocarbamate exposure and cancer incidence among male pesticide applicators in the Agricultural Health Study: a prospective cohort. Environ Health Perspect 116:1541-1546.

Waddell BL, Zahm SH, Baris D, Weisenburger DD, Holmes F, Burmeister LF, et al. 2001. Agricultural use of organophosphate pesticides and the risk of nonHodgkin's lymphoma among male farmers (United States). Cancer Causes Control 12:509-517.

White G, Cessna A. 1989. Occupational hazards of farming. Can Fam Physician 35:2331-2336.

Zahm SH, Weisenburger DD, Babbit PA, Saal RC, Vaught JB, Cantor KP, et al. 1990. A case-control study of non-Hodgkin's lymphoma and the herbicide 2,4 dichlorophenoxyacetic acid in Eastern Nebraska. Epidemiology 1:349-356.

Zheng T, Zahm SH, Cantor KP, Weisenburger DD, Zhang Y, Blair A. 2001. Agricultural exposure to carbamate pesticides and risk of non-Hodgkin lymphoma. J Occup Environ Med 43:641-649.

Received 25 November 2009

accepted 5 May 2010 